\title{
SYNOPSIS
}

News

ANALYSIS

- Practice

\section{Physician Resources}

\section{New neurosurgeons left jobless: Where's the plan?}

A trio of new neurosurgeons find themselves "disappointed" and "frustrated" that they have no choice but to head south of the border to get a job, after Canadian taxpayers invested an estimated $\$ 8$ million for each to get his specialist training.

"I feel personally let down," says Dr. Richard Perrin. "But I also think that Canadians in general are being let down, because Canadians have been paying for my education, or contributing to it, and they're not going to get anything back in the long run." Perrin along with Ashok Modha and John Sinclair, penned a letter to $C M A 7$ expressing shock over the discrepancy between the number of specialists being trained in Canada and available jobs for those graduates.

The trio are completing subspecialty fellowships and have either accepted, or are weighing, offers from American hospitals after coast-to-coast job searches in Canada proved fruitless.

Their predicament raises the question: Why are so many neurosurgeons being produced in the nation's medical schools?

Perrin argues the primary reason for the discrepancy between supply and demand is that governments aren't hiring enough neurosurgeons to achieve the objective of a neurosurgeon-too patient-ratio of 1:150 000, as opposed to the current 1:178 000 .

Achieving this ideal would require a one-time hire of 20-30 more neurosurgeons, according to the Canadian Neurosurgical Society (CNSS). Yet even if the ratio were met, Canada would still be overproducing neurosurgeons.

Each year 14 neurosurgical spots are set aside at medical schools. According to the CNSS, those graduates, along with foreign trainees, typically yield an annual flow of about 14-20 qualified specialists.

Upwards of $50 \%$ of newly qualified neurosurgeons now head to the US, says CNSS President Dr. Brian Wheelock; that averages out to about 7 per year at a cost of around $\$ 56$ million. (It costs \$550 000 annually for 4 years of medical school, and $\$ 900000$ per year for the 6 years of neurosurgical specialty training, for a total of $\$ 8$ million to train each specialist [CMAJ 1994;151(11):1581-7].)

And now the American Board of Neurological Surgery has decided that this year's crop is the last whose training meets their standards. That means there's going to be a "glut" of future graduates with no apparent place to go, says Wheelock.

Twenty positions from the current roster of 190 practising neurosurgeons will open up by the year 2010 as a result of retirements, says Wheelock. But the notion that at least 90 new neurosurgeons will be competing for 20 available Canadian positions through 2010 leaves Perrin horrified. "They're going to be flipping burgers," he says.

Wheelock and groups like the Royal College of Physicians and Surgeons of Canada and the umbrella National Specialty Societies of Canada (NSSC) are at a loss, saying they have no input whatsoever into such decisions because that's a matter between provincial governments and medical schools.

Association of Canadian Medical Colleges Executive Director Dr. David Hawkins says the number of specialty spots in each medical school is "negotiated" annually on a province-byprovince basis with local governments. The number is generally based on "historical pattern" and perceived long-term provincial need. "It's a bit of crystal-ball gazing, with a long timeline."

NSSC chair Dr. John Scovil says some specialties face serious shortages while others face apparent gluts. There's nothing in the way of a comprehensive, national physician resources plan that actually matches production of more than 50 types of medical specialists with need or demand within the system, Scovil says. In many disciplines, it's "difficult" to even obtain good data on the number of practising specialists, let alone match that to demographic need.

"What is needed is overall leadership on a national level,

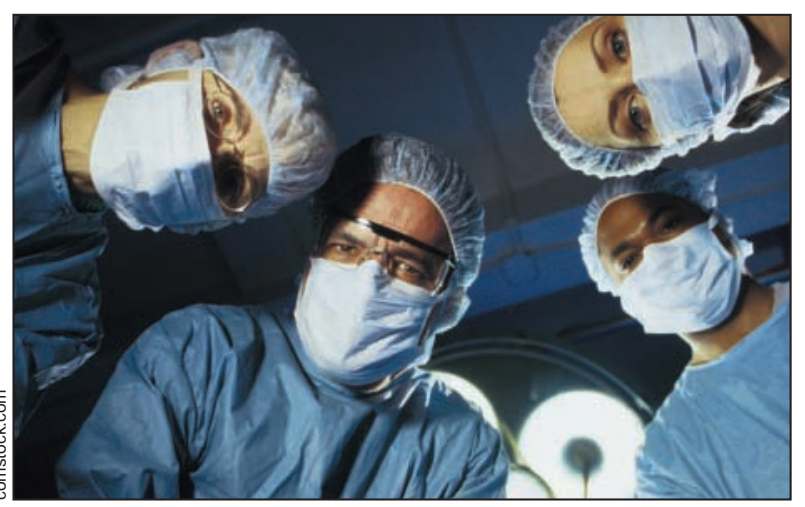

Some new specialists will be forced to go to the US until Canada develops a national physician-resource plan. 
including everyone. That's where we have to go to and we need to go soon because otherwise we're going to have a very big problem," Scovil says. "We need to have a good coordinated national plan and it needs to be specialty specific."

Hawkins says the National Co-ordinating Committee for Post-Graduate Medical Training sought unsuccessfully to develop a national physician resource plan in the 1990s but crashed on the shoals of intergovernmental jurisdictional wrangling. "I think we all feel [that] docs are a national resource [and] we should plan on a national level. It's just never happened."

That's scant consolation for Modha and his colleagues. "Why do we still have these huge, long waiting lists?" asks Modha. There are places in the country where people are waiting 3, 6, 9 months for surgery."

Modha has heard a raft of reasons why Canadian institutions had no room for their services: tight-fisted provincial governments, neurosurgeons resisting the hiring of another person who would cut available operating room time, and spots being saved for someone who was working his or her way through the system.

The 3 men are not happy about having to leave Canada. "When I started 15 years ago, I envisioned myself working in Canada," says Perrin.

Toronto neurosurgeon Dr. Mark Bernstein adds: "As Dr. Perrin's Fellowship supervisor, I can vouch that his leaving is Canada's loss. As long as our governments undervalue patients by undervaluing hardworking health care workers, the latter will continue to leave our great country." - Wayne Kondro, Ottawa

\section{Federal Politics}

\section{Public health on the installment plan}

Hoping to dispel impressions that the federal government was imprudent with taxpayers' dollars during the sponsorship scandal, Finance Minister Ralph Goodale unveiled a 2004-5 federal budget that provides relatively modest new monies to improve Canada's public health system.

The new Public Health Agency will absorb the functions of, and \$404-million in funding from, Health Canada's Population and Public Health Branch, while receiving an additional $\$ 165$ million over 2 years for operations, including administrative costs associated with its creation.

That falls well short of the $\$ 1.65$ billion over 5 years in new monies that the National Advisory Committee on SARS and Public Health, headed by University of Toronto Dean of Medicine Dr. David Naylor, recommended be pumped into the system.

Still, Naylor was enthusiastic. "Absent an agency that is operational and a chief public health officer in place to help guide its mandate, this is a very impor\& tant beginning." His opinion was echoed by the CMA.

Goodale stressed that the new outlays are but a "first installment" and the issue of financing will be revisited once a comprehensive public health plan is developed. The agency's broad goal is to increase public health capacity for chronic disease, emergency preparedness and infectious disease.

As it stands, the $\$ 165$ million will be divided among 5 priorities: emergency response capacity; disease surveillance; the creation of regional centres of excellence on communicable disease epidemiology; capital upgrades at the $\mathrm{Na}$ tional Microbiology Laboratory in Winnipeg and the Laboratory for Foodborne Zoonoses in Guelph; and improving international collaboration.

Health Canada officials projected the bulk of the new monies will go to human resources, particularly training the next generation of public health professionals through fellowships, communitybased apprenticeships and other initiatives.

It's not known where the agency's offices will be located, but Dr. Carolyn Bennett, Minister of State for Public Health, says it will be up and running by late May, when Canada's new public health officer is slated to be hired (see page 1425).

After a decade of cost containment, the agency is "a miracle for those toiling in public health," Bennett said at a media conference. "We've learned lessons from SARS but we have a lot to learn about using modern tech- nology and working together.'

She called for an end to the "tyranny of the acute. The sustainability of the system is about decreasing the demand side."

The budget also included funding for 3 provincial public health initatives. They will receive $\$ 300$ million over 3 years to standardize immunization of children and youth against 5 diseases: meningococcal infection, pneumococcal infection, chicken pox, pertussis and influenza.

The provinces will also be given $\$ 100$ million over 3 years to redress deficiencies in frontline public health infrastructure. Health Canada officials noted some provinces lack even a single isolation unit.

And finally, the provinces will receive $\$ 100$ million to buy software and hardware for disease surveillance systems in service of the Canada Health Infoway quest to improve health data collections.

While those are good starts, a comprehensive strategy is still wanting, argued Coalition for Active Living Chief Operating Officer Steve Grundy. "There has to be significant new investments in nutrition, tobacco control, immunization and physical activity if we're really going to make progress on public health." - Wayne Kondro, Ottawa 